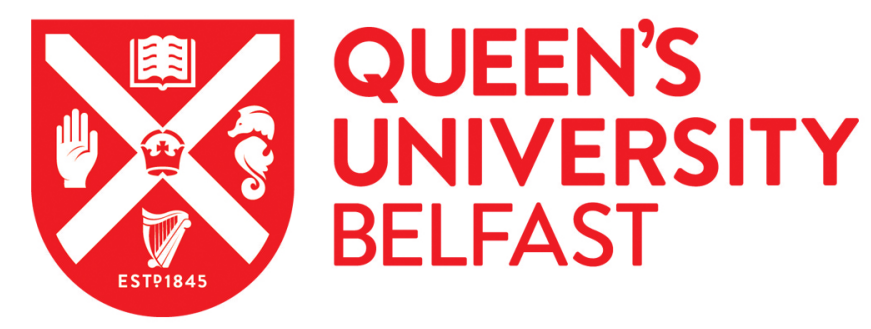

\title{
Pokémon GO or Pokémon Gone: How can cities respond to trends in technology linking people and space?
}

Adlakha, D., Marquet, O., Hipp, J. A., \& Tully, M. (2017). Pokémon GO or Pokémon Gone: How can cities respond to trends in technology linking people and space? Cities and Health, 1-6.

https://doi.org/10.1080/23748834.2017.1358560

Published in:

Cities and Health

Document Version:

Peer reviewed version

Queen's University Belfast - Research Portal:

Link to publication record in Queen's University Belfast Research Portal

Publisher rights

Copyright Talyor and Francis 2017 This work is made available online in accordance with the publisher's policies. Please refer to any applicable terms of use of the publisher.

\section{General rights}

Copyright for the publications made accessible via the Queen's University Belfast Research Portal is retained by the author(s) and / or other copyright owners and it is a condition of accessing these publications that users recognise and abide by the legal requirements associated with these rights.

Take down policy

The Research Portal is Queen's institutional repository that provides access to Queen's research output. Every effort has been made to ensure that content in the Research Portal does not infringe any person's rights, or applicable UK laws. If you discover content in the Research Portal that you believe breaches copyright or violates any law, please contact openaccess@qub.ac.uk. 
Pokémon GO or Pokémon Gone: How can cities respond to trends in technology linking people and space?

Deepti Adlakha, PhD

School of Natural and Built Environment

Queen's University Belfast

Belfast, Northern Ireland, UK

d.adlakha@qub.ac.uk

Oriol Marquet, PhD

Department of Parks, Recreation, and Tourism Management Center for Geospatial Analytics

North Carolina State University

Raleigh, North Carolina, USA

omarque@ncsu.edu

J. Aaron Hipp, PhD

Department of Parks, Recreation, and Tourism Management Center for Geospatial Analytics

Center for Human Health and the Environment

North Carolina State University

Raleigh, North Carolina, USA

jahipp@ncsu.edu

Mark A. Tully, PhD

UKCRC Centre of Excellence for Public Health (Northern Ireland)

Centre for Public Health

Queen's University Belfast

Belfast, UK

m.tully@qub.ac.uk 
In July 2016, the release of the augmented-reality mobile application-Pokémon GO-captivated mobile gamers across the world in a craze of virtual monster-hunting. Developed by Niantic for iOS, Android, and Apple Watch devices, Pokémon GO became a global phenomenon and dominated worldwide news media within the first few weeks of its launch. A week after its release in the US, the game had broken the Apple App Store's record for most number of downloads in a week. ${ }^{1}$ According to analysts, Pokémon GO generated about $\$ 600 \mathrm{~m}(\mathrm{f} 470 \mathrm{~m})$ in global revenue in its first three months and is still bringing in $\$ 120,000$ a day in the UK (as of 12/12/2016). ${ }^{2}$ It was the most used and profitable mobile app in 2016, ranking first place on the world's top-grossing charts of mobile apps. ${ }^{3}$

Soon after its release, initial reports suggested that Pokémon GO got many people moving more and exploring outdoor public spaces. This prompted public health researchers to ask whether Pokémon GO may be a cure for the physical inactivity epidemic. But for how long? Is Pokémon GO a passing fad or does its uptake have the potential to bring about long-term changes in people's physical activity? Can mobile games like Pokémon GO and other forms of technology create a lasting impact on social life and our interactions in the public realm, if any at all? This commentary discusses the evolution of mobile gaming, resulting changes in health and social behaviours and how cities can respond to trends in technology. We present the implications of augmented reality gaming on city design and health, and how these trends in emerging technologies can be leveraged to develop future health interventions to link people and place using active mobile games and exergames/ fitness games (games that rely on technology that tracks body movement or reaction).

Virtual mobile games have been around since the 1990's. ${ }^{4}$ However, a unique, distinguishing aspect of Pokémon GO compared to other virtual mobile games is its connection with urban spaces (as physical spaces) as well as the game's demand of physical play (it requires players to move around public space). Pokémon GO is the first widely selling, free-to-play, location-based augmented reality mobile game that is fully immersed into actual geographical space incorporating virtual, physical, and social dimensions. ${ }^{5}$ The game involves capturing virtual characters or Pokémon, that have been placed in prominent, real public locations, such as streets, parks, public spaces, and other notable public buildings and spaces. The app allows players to create their virtual avatar and uses a mobile device's GPS capability to display the player's current geographical location on a map. By placing the user in a real-world location, the app allows them to locate, capture and train the Pokémon characters that appear on the screen as if they were in the same location as the player. Additional benefits can be collected via visits to specific locations (known as "Pokestops") and characters can be made to battle with other players' characters.

\section{Pokémon GO and People-Space Interactions}

The widespread popularity of Pokémon $\mathrm{GO}$ and its ability to get people walking highlights new beginnings for gamification of health and the social life of urban spaces. Researchers have found that players interact in various ways with their smartphones and physical surroundings while playing an augmented reality game. ${ }^{6}$ Mobile games (e.g., Pokémon GO, Ingress, Turf Wars, Zombies, Run!?) have notable implications for the way in which people move and interact with public spaces. For example, they can motivate populations to get more active by encouraging people to explore their local communities and in the process, introduce them to new spaces and opportunities for social interaction. Reports analysing social media posts on Pokémon GO have indicated that as people spend more time outside gaming, they are not only watching their smartphone screen, but also interacting with their physical surroundings off-screen as well as other players. After playing the 
game for 30 minutes, users reported discovering new features in the environment, prompting an increase in awareness, excitement and curiosity of surroundings. ${ }^{8}$ 


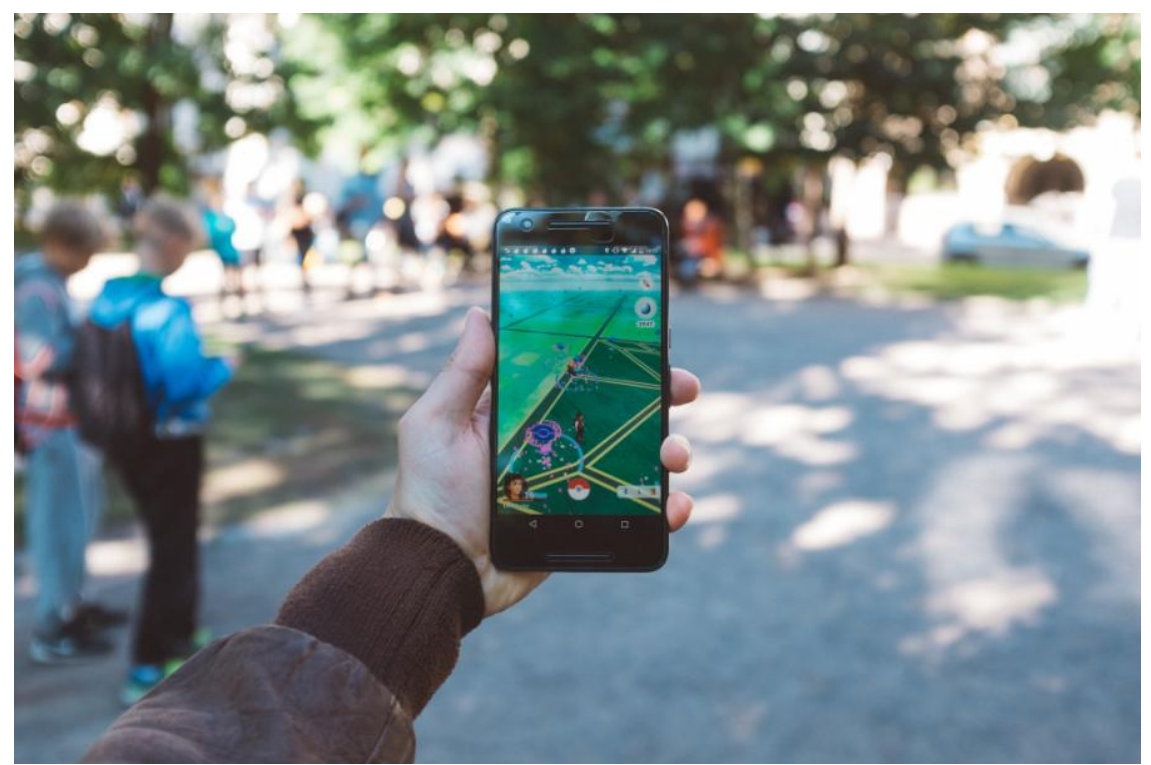

Figure 1. Photograph showing a player capturing virtual characters or Pokémon in a real-world location (Picture courtesy: Creative Commons https://creativecommons.org/) 


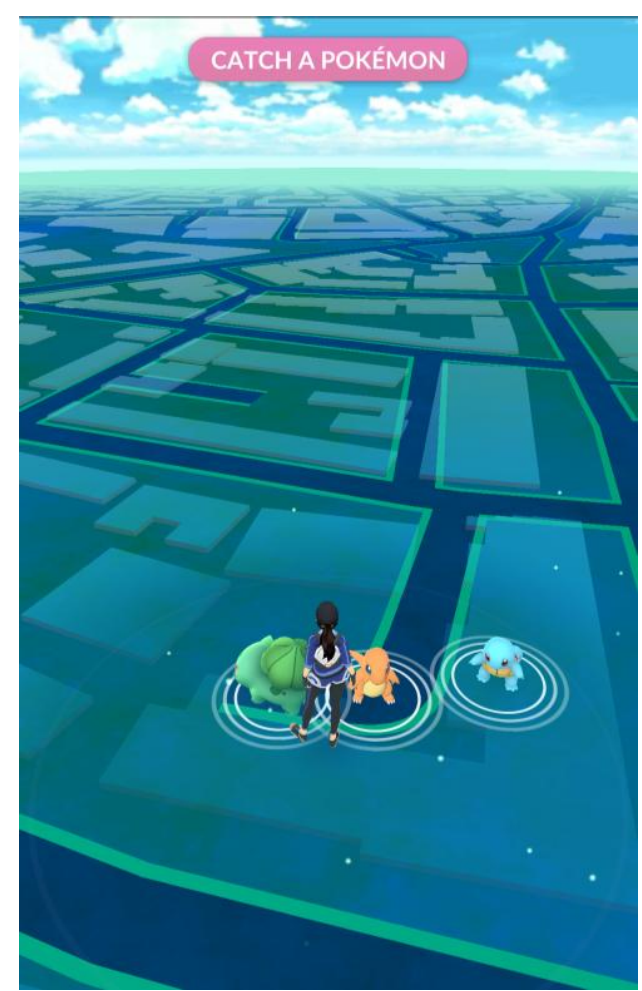

Figure 2. Screenshot of Pokémon GO on a player's phone showing the player's virtual avatar in a real world geographical space and the virtual characters or Pokémon that appear nearby (Picture courtesy: Dr. Deepti Adlakha)

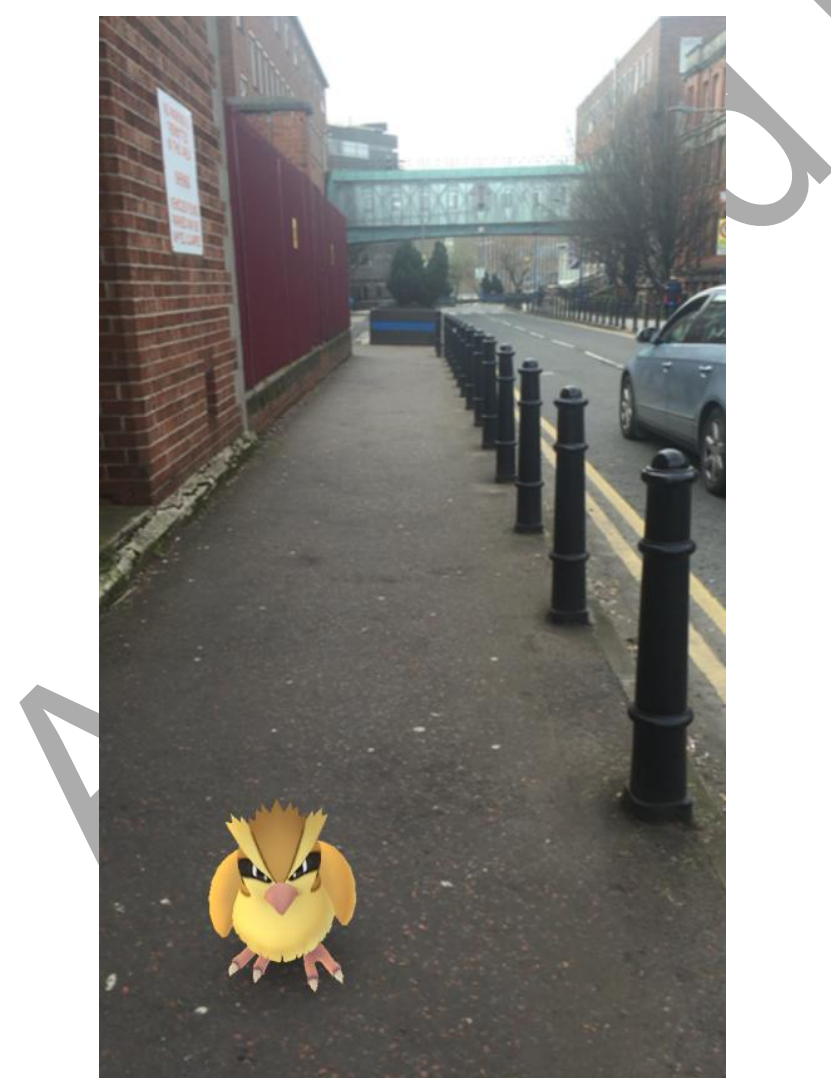

Figure 3. Screenshot of Pokémon GO on a player's phone showing a virtual Pokémon on a public sidewalk (Picture courtesy: Dr. Mark A. Tully) 


\section{Mobile Gamification and Physical Activity}

Across the world, governments, health advocates, and public health researchers have been exploring methods and interventions to promote regular physical activity. Despite this, results have been inconsistent and physical activity levels have been declining worldwide. ${ }^{9}$ Adults and children in many countries around the world do not get recommended amounts of physical activity. ${ }^{10,11}$ Early research suggests that playing Pokémon GO appears to increase daily physical activity levels particularly among groups that have low levels of activity-teens, preteens, and younger adults. ${ }^{12,13}$ A recent study estimated that the game added a total of 144 billion steps to Americans' physical activity during the first 30 days after they started playing it. ${ }^{6}$

A key part of the game experience is the fact that the game will not function if the player is travelling over a certain speed, which ends up making the game only playable when using active modes of transport (i.e., walking or biking). ${ }^{14}$ Whereas Pokémon $\mathrm{GO}$ is not strictly an exergame-as physical activity is not a direct aim of the game-it does include some functionalities that are only unlocked when certain walking thresholds are met. ${ }^{6,12,15,16} \mathrm{It}$ is unlikely that Pokémon GO players are walking fast enough to get the full range of health benefits from being physically active. Research shows that in order to accrue any physical health benefits, an individual needs to be moving at a minimum of a brisk walk around three miles an hour, for at least ten minutes. ${ }^{26}$ However, Pokémon GO players can incur some musculoskeletal benefits by breaking up sedentary activity with brief bouts of movement from playing the game ${ }^{27}$, as well as improve mental wellbeing by being outdoors, exploring and connecting with the environment and other people. ${ }^{28,29}$

Socio-demographic information on players is limited, but results from a US-based survey conducted seven days after Pokémon GO's release in July 2016 show that African Americans, Hispanics and women embraced Pokémon $\mathrm{GO}$ in far greater numbers than previous versions of the Pokémon franchise, which debuted in the US in $1998 .{ }^{17}$ Nearly half of African American players (49\%), $40 \%$ of Hispanics and $47 \%$ of females said Pokemon GO was their first foray into the virtual world of monster-hunting. Pokémon GO also attracted new players among Caucasians (32\%), AsianAmericans (31\%), and males (21\%). ${ }^{17}$

Social media reports on Pokémon GO provide early, yet compelling indicators that a key part of the game is its social aspect. This suggests that interventions to promote physical activity should use the social dimensions of environments in order to make them appealing and successful in promoting long-term behavioural change, supporting previous research. ${ }^{18,19}$ Research has also found that games like Pokémon GO and Ingress that incorporate GPS location-based augmented reality and include social interaction and community gamification features are more efficient at promoting physical activity than other mobile games. ${ }^{20,21}$ Increased socialisation and a higher number of visits to green areas and public parks were among the most reported benefits of the Pokémon GO craze. ${ }^{30}$ Whether sustained and regular use of the app can improve not only physical activity but also mental health, social capital and social interactions remains to be explored. From a public health standpoint, this involves understanding and measuring the effects of these type of interventions and the social dimensions of our cities in a holistic manner. Mixed method designs including qualitative research are ideal for this purpose, as they can incorporate measurement of key behavioural outcomes to examine the full range of tangible benefits for possible future measurement. ${ }^{18}$

Leveraging mobile technology that captures the attention of youth and young adults in an effort to improve their activity levels and health outcomes in later life has great potential for population research. However, it is important to note the limitations of this type of technology. There have been several critiques and concerns about Pokémon GO-players' concerns about safeguarding issues, accidents, instances of distracted driving, millennials' lack of interaction with the real world while preoccupied with the mobile game, and numerous examples of unintended consequences 
such as reports of players so absorbed in the virtual world they ignore trip hazards-are some of the reasons the game has attracted negative press. ${ }^{22}$ The game has also attracted controversy for becoming a public nuisance at some locations and contributing to accidents with drivers or pedestrians preoccupied while playing Pokémon $\mathrm{GO} .{ }^{23-25}$ Studies have also highlighted inequitable access by players from ethnic minorities, who might face dangers and threats while playing Pokémon $\mathrm{GO}^{22}$

\section{Augmented Reality Games and the Public Realm}

The public realm is a social setting and typically includes urban public spaces, such as a city's streets, markets, parks and plazas, and is part of a much larger public sphere. ${ }^{31}$ These public places are host to planned encounters with existing acquaintances, as well as to serendipitous encounters with strangers. ${ }^{32}$ Augmented reality prompts us to re-examine our notions of the public realm and our interactions with it. By layering its simulated elements over the real world, the public realm may be evolving into a hybrid space incorporating a combination of human face-to-face interactions and virtual ones. The extensive influence of Pokémon GO encourages us to reconsider not only how people use public spaces, but also the ways in which technology is interwoven with the public realm. Technological trends may have the potential to influence our social networks, how we maintain them, access local information, as well as how we move in, use and engage with public spaces.

As these types of mobile games and technology evolve, there are several implications for the design of cities and public spaces. From a cities and public health perspective, mobile gaming apps like Pokémon GO may signal a shift in person-in-environment interactions prompting us to reassess the design of the built environment in order to cater to them. Humans are social beings and need to have a reason to be, linger or stay in a particular place, and a public space that draws people provides lots of reasons for them to be there. ${ }^{33}$ In several ways, Pokémon GO has supplemented this by offering people one more reason to be out in their public spaces and communities. It has created a virtual community of users that in many ways is real and visible in public.

The fact that Pokémon GO has brought people out into public spaces highlights the importance of programming for activities and events in public spaces. Research on wireless usage and the social role of urban design has shown that some technology users are cut off from their surroundings, but for most, interactions between on- and off-line experiences increase exposure to social diversity. ${ }^{34}$ Public spaces have an inherent capacity to promote exposure to diversity by minimizing segregation of people based on lifestyle and social characteristics. ${ }^{32,34}$ This provides yet another reason to invest in the design of public spaces that attract people to stay, to organize their social interactions and promote a sense of belonging. Cities and institutions can also benefit from the popularity and the social component of the game to promote and engage outdoor events. A recent example of that is the alliance between Niantic and the Knight Foundation to gamify urban events like OpenStreets. ${ }^{26,}$ ${ }^{27}$ Communities may also need to advocate for education, law enforcement, civic engagement and other interventions to stem the threat posed by distracted driving, making a compelling case to invest in street infrastructure and policies to promote safer walking and active travel, subsequently making it safer to play the game.

As an intervention in itself, Pokémon GO has the potential to guide large-scale interventions for increasing physical activity that could be leveraged for public health purposes. Physically engaging mobile gaming apps like Pokémon GO that get people walking outdoors present a perfect opportunity to design and improve city spaces to be more walkable, vibrant, and welcoming. They can also encourage creation of physical activity support groups within communities, which can be an effective, low-cost method of increasing walking. These steps can guide interventions to promote walking and other forms of physical activity in parks, green spaces and other public spaces. What makes Pokémon GO particularly powerful is that it attracts people with its game mechanics and 
makes physical activity a secondary outcome. The motivation and engagement of the players comes thus not from turning physical activity into a game, but from a game with its own purpose, that incorporates being active as part of the gaming experience. ${ }^{16}$ Incorporating mobile gamification for promotion of physical activity can encourage users to walk considerable lengths (e.g., up to $10 \mathrm{~km}$ ) to places they may not have visited before, interact with others socially in public spaces, and continue to sustain and increase their physical activity as the game progresses. ${ }^{6,12,17}$ There is substantial evidence that public health initiatives designed to increase physical activity have found the promotion of social support for physical activity in community settings to be effective. ${ }^{10,11}$ Research has indicated social support interventions and other community-based interventions aimed at promoting physical activity to be cost-effective public health strategies for preventing chronic disease. ${ }^{26}$

Extending beyond the virtual dimension of mobile gaming, apps like Pokémon GO may have the potential to incorporate actual physical activity requirements for players to be successful and promote face-to-face social interactions between these players. ${ }^{35}$ Other potential benefits derived from the huge popularity of the game and broad age-span of players, might include better intergenerational relationships as parents and kids engage together in outdoor activities. ${ }^{17,28}$ Other unknown long-term benefits can also arise from people exploring their environment from the pedestrian perspective, either by raising player's awareness of the disadvantages of car-oriented developments or by making them reconsider their usual transportation habits.

The beneficial effects of apps like Pokémon GO and related technologies on human behaviour change remains to be tested. However, they are beginning to alter the way inactive people interact with their environments by giving them incentives to get up and move. ${ }^{36}$ Among youth that are highly involved with social media and video games, mobile games may have the potential to improve physical activity levels and lead to longer-term behavioural changes. Although the above literature on motives for playing video and online games is informative, it is important to note that these findings may not reflect the full spectrum of motives and challenges of playing mobile games (e.g., entertainment, mobility, access to smartphones and GPS technology, etc.). ${ }^{37}$ We believe existing theoretical models are unable to explain the role of augmented reality games for the study of urban spaces. Whether this type of gamification can ensure that physical activity becomes a regular habit among its users remains to be tested. ${ }^{12}$ It will be interesting to evaluate if players are seeing a corresponding spike in physical activity levels from pedometer or accelerometer data and are now meeting their daily step targets as they chase down elusive Pokémon. More research is necessary to show users' intensity of physical activity, the social and psychological wellbeing benefits of augmented reality mobile gaming and whether they will translate into long-term physical activity behaviours and motivations.

Overall, the game has potential benefits that need proper research for validation and future interventions. Understanding how to design mobile games for public health interventions and subsequent interaction in outdoor city spaces will be important in a future with an ever more presence of mobile games and virtual reality experiences. Specifically, if technology developers, urban designers, and researchers begin to collaborate, this emerging novel integrative genre of gaming can be applied for design of urban spaces to increase active engagement amongst inactive populations.

\section{References}

1. Digital Stat. Hot game: Amazing Pokémon Go statistics. 201622 July 2016]; Available from: http://expandedramblings.com/index.php/pokemon-go-statistics/

2. Dave Lee. Pokemon Go update seeks to revive interest. 2016 [Accessed 19 December 2016]; Available from: http://www.bbc.com/news/technology-38291993 
3. Perez S. Pokémon Go tops Twitter's daily users, sees more engagement than Facebook. . 2016 July 132016 ]; Available from: https://techcrunch.com/2016/07/13/pokemon-go-topstwitters-daily-users-sees-more-engagement-than-facebook/

4. Willson M, Leaver T. Social, Casual and Mobile Games: The Changing Gaming Landscape. Bloomsbury Publishing; 2016.

5. American Heart Assocation. Pokémon Go brings video games outside. 2016 [Accessed 5 October 2016]; Available from: http://news.heart.org/pokemon-go-brings-video-games-outside/ 6. Althoff T, White RW, Horvitz E. Influence of Pokémon Go on Physical Activity: Study and Implications. Journal of Medical Internet Research 2016;18(12):1.

7. Vasiliu A. 8 Location Based Games for Android and iOS (besides Ingress). 2015 [Accessed 5 February 2017]; Available from: http://www.pocketmeta.com/8-gps-based-games-for-android-andios-30708/

8. Miranda MH, Knöll SM. Learning about healthy places with a location-based game; 2016.

9. Andersen LB, Mota J, Di Pietro L. Update on the global pandemic of physical inactivity. The Lancet 2016;388(10051):1255-1256.

10. Hallal PC, Andersen LB, Bull FC, Guthold R, Haskell W, Ekelund U. Global physical activity levels: surveillance progress, pitfalls, and prospects. The Lancet 2012;380(9838):247-257.

11. Sallis JF, Cerin E, Conway TL, Adams MA, Frank LD, Pratt M, et al. Physical activity in relation to urban environments in 14 cities worldwide: a cross-sectional study. The Lancet 2016;387(10034):2207-2217.

12. Howe KB, Suharlim C, Ueda P, Howe D, Kawachi I, Rimm EB. Gotta catch'em all! Pokémon GO and physical activity among young adults: difference in differences study. BMJ 2016;355.

13. The Daily Dot. 'Pokémon Go' is so addictive that people are getting way more exercise than they're used to. 201622 July 2016]; Available from: http://www.dailydot.com/debug/pokemon-goworkout-exercise-perk/

14. Sharma P, Vassiliou V. Pokémon Go: cardiovascular benefit or injury risk? Oxford Medical Case Reports 2016;2016(10):omw085.

15. Whitehead A, Johnston $\mathrm{H}$, Nixon N, Welch J. Exergame effectiveness: what the numbers can tell us. In: Proceedings of the 5th ACM SIGGRAPH Symposium on Video Games. Los Angeles, California: ACM; 2010. p. 55-62.

16. King D, Greaves F, Exeter C, Darzi A. 'Gamification': influencing health behaviours with games. Journal of the Royal Society of Medicine 2013;106(3):76-8.

17. MFour Mobile Research. Research Shows That Pokemon Go Boosts Friendships and Social Cohesion. 2016 [Accessed 1 February 2017]; Available from:

https://rwconnect.esomar.org/research-shows-that-pokemon-go-boosts-friendships-and-socialcohesion/

18. Clark AM, Clark MTG. Pokemon Go and Research: Qualitative, Mixed Methods Research, and the Supercomplexity of Interventions. International Journal of Qualitative Methods 2016:1-3.

19. McNeill LH, Kreuter MW, Subramanian SV. Social environment and physical activity: a review of concepts and evidence. Social Science and Medicine 2006;63(4):1011-22.

20. Tong X, Gromala D, Shaw CD, Choo A. A Field Study: Evaluating Gamification Approaches for Promoting Physical Activity with Motivational Models of Behavior Changes. In: Kurosu M, editor. Human-Computer Interaction. Novel User Experiences: 18th International Conference, $\mathrm{HCl}$ International 2016, Toronto, ON, Canada, July 17-22, 2016. Proceedings, Part III. Cham: Springer International Publishing; 2016. p. 417-424.

21. Barnett LM, Bangay S, McKenzie S, Ridgers ND. Active Gaming as a Mechanism to Promote Physical Activity and Fundamental Movement Skill in Children. Frontiers in Public Health 2013;1:74.

22. Joseph B, Armstrong DG. Potential perils of peri-Pokémon perambulation: the dark reality of augmented reality? Oxford Medical Case Reports 2016;2016(10):omw080. 
23. BBC. Thousands play Pokemon Go while driving, US research suggests. 2016 [Accessed 17 September 2016]; Available from: http://www.bbc.co.uk/newsbeat/article/37395530/thousandsplay-pokemon-go-while-driving-us-research-suggests

24. Ayers JW, Leas EC, Dredze M, Allem JP, Grabowski JG, Hill L. Pokemon GO-A New Distraction for Drivers and Pedestrians. JAMA Intern Med 2016;176(12):1865-1866.

25. Rutkin A. Help, my yard's a Pokéstop. New Scientist 2016;231(3083):22.

26. World Health Organization. Global Recommendations on Physical Activity for Health. In: Global Strategy on Diet, Physical Activity and Health. Geneva: World Health Organization; 2010. 27. Schilling D. Is Pokémon Go the answer to America's obesity problem? . 2016 July 13 2016]; Available from: https://www.theguardian.com/commentisfree/2016/jul/13/is-pokemon-go-theanswer-to-obesity-america.

28. Kato TA, Teo AR, Tateno M, Watabe M, Kubo H, Kanba S. Can Pokémon GO rescue shut-ins (hikikomori) from their isolated world? Psychiatry and Clinical Neurosciences 2016:n/a-n/a.

29. Tateno M, Skokauskas N, Kato TA, Teo AR, Guerrero APS. New game software (Pokémon Go) may help youth with severe social withdrawal, hikikomori. Psychiatry Research 2016;246:848-849.

30. Wagner-Greene VR, Wotring AJ, Castor T, Kruger J, Mortemore S, Dake JA. Pokémon GO: Healthy or Harmful? American Journal of Public Health 2016;107(1):35-36.

31. Gehl J, Gemzoe L. Public Spaces, Public Life. Danish Architectural Press; 2004.

32. Hampton KN, Livio O, Sessions Goulet L. The Social Life of Wireless Urban Spaces: Internet Use, Social Networks, and the Public Realm. Journal of Communication 2010;60(4):701-722.

33. Whyte WH. The Social Life of Small Urban Spaces. Washington, D.C.: The Conservation Foundation; 1980.

34. Hampton KN, Livio O, Sessions L. The Social Life of Wireless Urban Spaces: Photo Essay. Contexts 2010;9(4):52-57.

35. Middelweerd A, Mollee JS, van der Wal CN, Brug J, Te Velde SJ. Apps to promote physical activity among adults: a review and content analysis. Int J Behav Nutr Phys Act 2014;11(97).

36. Boulos MN, Yang SP. Exergames for health and fitness: the roles of GPS and geosocial apps. Int J Health Geogr 2013;12(18).

37. Chia-chen Y, Dong L. Motives Matter: Motives for Playing Pokémon Go and Implications for Well-Being. Cyberpsychology, Behavior, and Social Networking;20(1):52-57. 